\title{
SISTEM INFORMASI MANAJEMEN PENYIMPANAN BAHAN MAKANAN MENGGUNAKAN PHP DAN MYSQL (STUDI KASUS: INSTALASI GIZI RUMAH SAKIT PERTAMINA BALONGAN INDRAMAYU)
}

Maudyna Gita Pratiwi ${ }^{1}$, Tias Beni Purabaya ${ }^{2}$

AMIK Purnama Niaga Indramayu, Jawa Barat, Indonesia maudy.cemod@gmail.com, tiasbeni.p@gmail.com

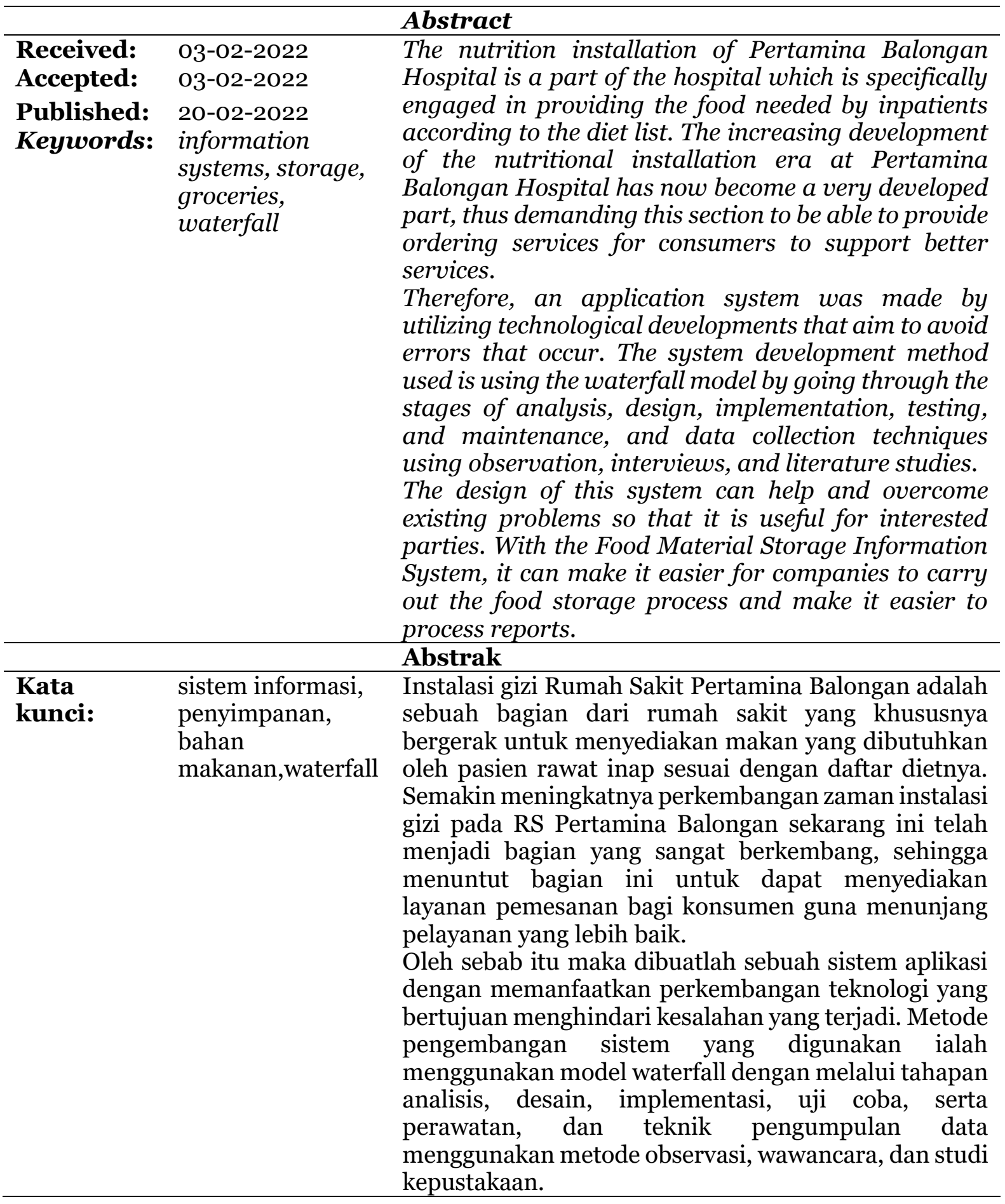


Perancangan sistem ini dapat bisa membantu dan mengatasi permasalahan yang ada sehingga bermanfaat bagi pihak-pihak yang berkepentingan. Dengan adanya Sistem Informasi Penyimpanan Bahan Makanan tersebut bisa memudahkan perusahaan untuk melakukan proses penyimpanan bahan makanan dan mempermudah melakukan pengolahan laporan.

Corresponding Author: Maudyna Gita Pratiwi E-mail: maudy.cemod@gmail.com

\section{PENDAHULUAN}

Perkembangan sistem informasi mengalami kemajuan yang sangat pesat, hal ini diakibatkan karena banyaknya dan beranekaragamnya data yang harus diolah dan disajikan dalam bentuk informasi, Sehingga penanganan sistem yang handal sangat dibutuhkan untuk menyelesaikan masalah tersebut. Tidak mudah untuk membuat sebuah laporan dengan menggunakan sistem manual maka mau tidak mau hampir semua aspek pekerjaan sudah beralih kedalam pengolahan data secara komputerisasi dengan cara ini dianggap lebih efektif (Effendy \& Mulyono, 2020).

Rumah Sakit Pertamina Balongan Indramayu merupakan rumah sakit swasta yang cukup besar di Indramayu, jadi rumah sakit ini memerlukan bahan makanan yang cukup banyak untuk memenuhi kebutuhan pasien (Gayatri, 2009). Dalam pengolahan datanya, dibutuhkan sistem informasi pengolahan data bahan makanan kering dan bahan makanan basah yang akurat dan tepat waktu. Untuk itu dengan mengetahui gambaran dan kualitas suatu sistem informasi pengolahan data bahan makanan kering dan bahan makanan basah menjadi suatu masalah yang menarik untuk dikaji, baik untuk kepentingan penulis maupun kepentingan rumah sakit (Alhamidy, 2006).

Permasalahan pada penelitian sebelumnya, Instalasi gizi Rumah Sakit Pertamina Balongan Indramayu yaitu belum memilikinya sistem informasi dalam pengelolaan penyimpanan bahan makanan. Selain itu manajemen instalasi gizi yang belum tertata dengan baik, pengolahan data penyimpanan bahan makanan yang manual, menjadikan admin gizi pada ruangan instalasi gizi kesulitan dalam mengolah data dan membutuhkan waktu yang lama dalam mendapatkan informasi. Aplikasi yang digunakan masih bersifat desktop sehingga mempersulit ruang gerak pengawasan, sehingga perlu adanya pengembangan sistem.

Untuk mengatasi masalah tersebut dibutuhkan sistem manajemen yang bisa diakses dengan mudah, kapan dan dimana saja oleh admin gizi serta memberikan informasi yang tepat, cepat dan akurat mengenai data penyimpanan bahan makanan di Rumah Sakit Pertamina Balongan. Atas dasar tersebut permasalahan diatas dikembangkan sistem informasi penyimpanan bahan makanan berbasis web.

Proses pelayanan di dalam Sistem Informasi Penyimpanan Bahan Makanan ini menggunakan interface untuk lebih memudahkan dan mengefisiensi sumber daya yang ada, serta meningkatkan kinerja pada Sistem Informasi Penyimpanan Bahan Makanan dalam mengelolah data dan menyajikan informasi dengan cepat dan akurat (Syafar, 2012). Program aplikasi yang digunakan untuk membuat aplikasi ini adalah dengan PHP dan MySQL sebagai media penyimpanan data.

Berdasakan latar belakang masalah yang ada, peneliti tertarik untuk melakukan penelitian tentang "Sistem Informasi Manajemen Persediaan Bahan Makanan di Instalasi Gizi Rumah Sakit Pertamina Balongan”.

Tujuan penelitian ini adalah untuk membuat Sistem Informasi Penyimpanan Bahan Makanan di Instalasi Gizi Rumah Sakit Pertamina Balongan Indramayu agar mengefisiensikan sistem lama atau sistem yang sedang berjalan, sehingga pengguna dapat lebih mudah untuk melakukan transaksi. 


\section{METODE PENELITIAN}

Menurut (Rosa, 2016) menyatakan bahwa Metode SDLC (System Development Life Cycle, Siklus Hidup Pengembangan Sistem) atau System Life Cycle (Siklus Hidup Sistem) adalah proses pembuatan dan pengubahan sistem serta model dan metodologi yang digunakan orang untuk mengembangkan sistem-sistem perangkat lunak sebelumnya (berdasarkan best practice atau cara-cara yang sudah teruji baik).”

SDLC (System Development Life Cycle) memiliki beberapa model dalam penerapan dan tahapan prosesnya. Namun Pada penelitian ini, model pengembangan sistem informasi yang digunakan adalah model waterfall, dimana tahapan yang dikerjakan melalui beberapa tahap, yaitu:

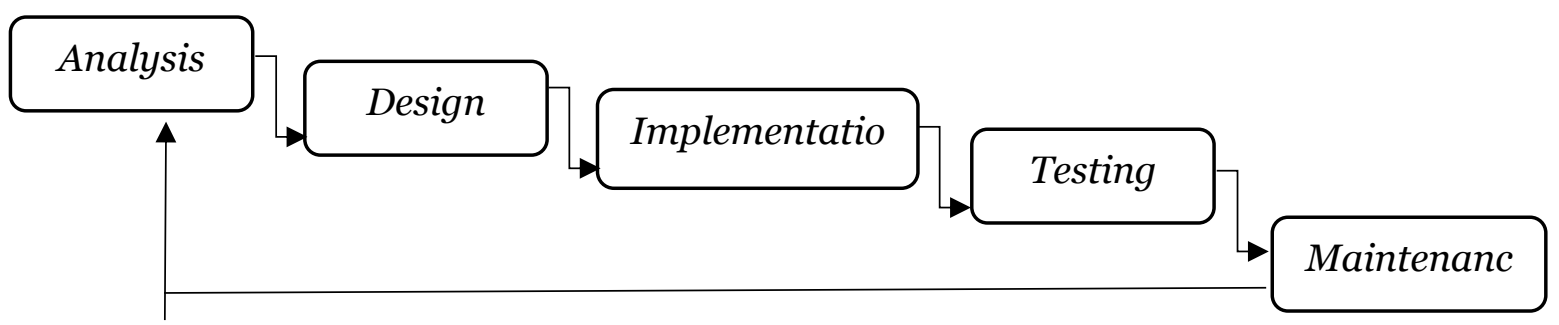

Sumber : (Bassil, 2012)

\section{Gambar 1. Tahapan Metode Waterfall}

Analisis dalam tahapan ini dilakukan wawancara atau observasi untuk mengumpulkan data-data yang dibutuhkan dengan menganalisis secara langsung di tempat yang jadikan sampel.

1. Desain

Penulis akan melakukan perancangan sistem berdasarkan analisis kebutuhan yang telah dilakukan. pada saat melakukan perancangan sistem yang mengacu terhadap sistem yang sudah ada, pada bagian ini penulis hanya mengembangkan bagian yang masih belum memenuhi kebutuhan user.

2. Implementasi

Setelah penulis memperoleh semua kebutuhan dari user. Setelah itu akan dibangun sistem yang mencakup kebutuhan user. Penulis melakukan testing untuk mengetahui apakah sistem yang dibuat sudah sesuai dengan kebutuhan user atau belum.

3. Pengujian

Penulis melakukan pengujian sistem yang telah dibuat pada perangkat keras user apakah sesuai dengan kebutuhan user.

4. Perawatan

Pada tahap ini penulis melakukan perawatan untuk menjaga sistem agar tetap terjaga dan terawat seperti tidak terjadi error, meminimalisir adanya kesalahan sistem dan lain-lain.

Dalam penelitian ini, penulis menggunakan beberapa metode penelitian untuk memperoleh data diantaranya adalah :

1. Observasi

Observasi adalah suatu cara pengumpulan data dengan pengamatan langsung dan pencatatan secara sistematis terhadap objek yang akan diteliti (Hasanah, 2017). Observasi dilakukan oleh peneliti dengan cara pengamatan dan pencatatan mengenai pelaksanaan pengadaan, permintaan, penyimpanan, dan pengeluaran bahan makanan kering dan bahan makanan basah pada Instalasi Gizi Rumah Sakit Pertamina Balongan Indramayu.

2. Wawancara

Wawancara dilakukan dengan petugas/operator yang melakukan transaksi. Wawancara dalam penelitian ini dilakukan untuk mengetahui tanggapan petugas dan pengurus masjid terhadap pelaksanaan transaksi yang telah dilaksanakan. 
Maudyna Gita Pratiwi, Tias Beni Purabaya

Sistem Informasi Manajemen Penyimpanan Bahan Makanan Menggunakan PHP dan MYSQL (Studi Kasus: Instalasi Gizi Rumah Sakit Pertamina Balongan Indramayu)

\section{Studi Pustaka}

Teknik ini digunakan untuk memperoleh dasar-dasar dan pendapat secara tertulis yang dilakukan dengan cara mempelajari berbagai literatur yang berhubungan dengan masalah yang diteliti (Hamzah, 2021). Hal ini juga dilakukan untuk mendapatkan data sekunder yang akan digunakan sebagai landasan perbandingan antara teori dengan prakteknya di lapangan. Data sekunder melalui metode ini diperoleh dengan browsing di internet, membaca berbagai literatur, hasil kajian dari peneliti terdahulu, catatan perkuliahan, serta sumber-sumber lain yang relevan.

\section{HASIL DAN PEMBAHASAN}

Perancangan database yang digunakan:

a. Tabel User

Tabel 1. Database User

\begin{tabular}{llll}
\hline No & Nama Field & Tipe Data & Keterangan \\
\hline $\mathbf{1}$ & *id & $\operatorname{Int}(11)$ \\
\hline $\mathbf{2}$ & Nama & Varchar(50) & \\
\hline 3 & Username & Varchar(50) & \\
\hline 4 & Password & Varchar(8) & \\
\hline 5 & Level & Varchar(10) &
\end{tabular}

b. Tabel Barang

Tabel 2. Database Barang

\begin{tabular}{|c|c|c|c|}
\hline No & Nama Field & Tipe Data & Keterangan \\
\hline 1 & *id_brg & $\operatorname{int}(11)$ & \\
\hline 2 & nama_barang & Varchar(500) & \\
\hline 3 & Kategori & Varchar(100) & \\
\hline 4 & Stok & Varchar(255) & \\
\hline 5 & Satuan & Varchar(100) & \\
\hline 6 & Expired & Varchar(30) & \\
\hline 7 & tgl_input & Varchar(30) & \\
\hline
\end{tabular}

c. Tabel Barang Keluar

Tabel 3. Database Barang Keluar

\begin{tabular}{llll}
\hline No & Nama Field & Tipe Data & Keterangan \\
\hline 1 & *id_brg & $\operatorname{Int}(11)$ & \\
\hline 2 & id_barang & $\operatorname{Int}(11)$ & \\
\hline 3 & qty & $\operatorname{Int}(11)$ \\
\hline 4 & tgl_input & $\operatorname{Varchar}(30)$ & \\
\hline 5 & user & Varchar(10) & \\
\hline
\end{tabular}

d. Tabel Barang Masuk

Tabel 4. Database Barang Masuk

\begin{tabular}{llll}
\hline No & Nama Field & Tipe Data & Keterangan \\
\hline 1 & *id_brg & $\operatorname{Int}(11)$ & \\
\hline 2 & id_barang & $\operatorname{Int}(11)$ & \\
\hline 3 & qty & $\operatorname{Int}(11)$ & \\
\hline
\end{tabular}


Maudyna Gita Pratiwi, Tias Beni Purabaya

Sistem Informasi Manajemen Penyimpanan Bahan Makanan Menggunakan PHP dan MYSOL (Studi Kasus: Instalasi Gizi Rumah Sakit Pertamina Balongan Indramayu)

\begin{tabular}{lll}
4 & tgl_input & Varchar(30) \\
\hline 5 & user & Varchar(10)
\end{tabular}

e. Tabel Kategori

Tabel 5. Database Kategori

\begin{tabular}{llll}
\hline No & Nama Field & Tipe Data & Keterangan \\
\hline 1 & *id_kat & $\operatorname{Int}(11)$ \\
\hline 2 & nama_kategori & Varchar(100) & \\
\hline
\end{tabular}

f. Tabel Permintaan

Tabel 6. Database Permintaan

\begin{tabular}{llll}
\hline No & Nama Field & Tipe Data & Keterangan \\
\hline 1 & *id & $\operatorname{Int}(11)$ \\
\hline 2 & id_brg & Varchar(10) & \\
\hline 3 & qty & Varchar(50) \\
\hline 4 & tgl & Date \\
\hline 5 & status & Varchar(10) \\
\hline 6 & user & Varchar(10) \\
\hline
\end{tabular}

g. Tabel Perawat

Tabel 7. Database Perawat

\begin{tabular}{|c|c|c|c|}
\hline No & Nama Field & Tipe Data & Keterangan \\
\hline 1 & *id & $\operatorname{Int}(11)$ & \\
\hline 2 & nama_ruangan & Varchar(100) & \\
\hline 3 & jumlah & Varchar(100) & \\
\hline
\end{tabular}

h. Tabel Satuan

Tabel 8. Database Satuan

\begin{tabular}{llll}
\hline No & Nama Field & Tipe Data & Keterangan \\
\hline 1 & *id_satuan & $\operatorname{Int}(11)$ \\
\hline 2 & nama_satuan & $\operatorname{Varchar}(100)$ & \\
\hline
\end{tabular}

1. Desain Perancangan Program

Tampilan Perancangan Input

a. Form Login

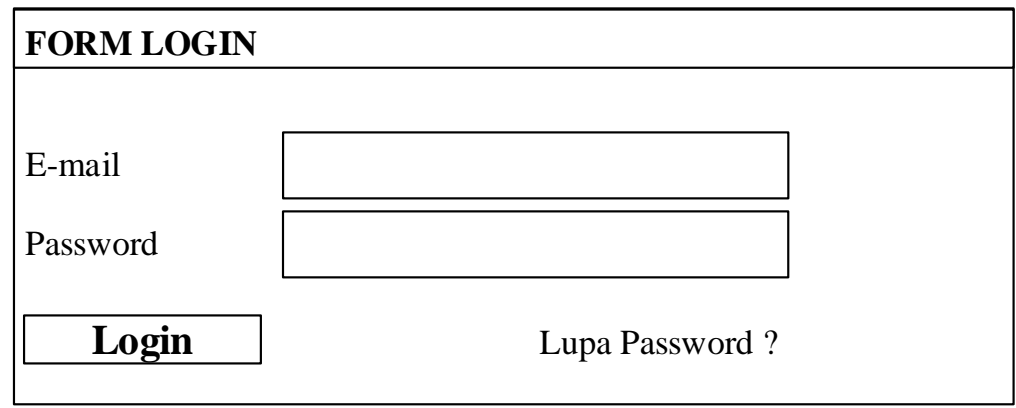

Gambar 2. Desain Login 
Maudyna Gita Pratiwi, Tias Beni Purabaya

Sistem Informasi Manajemen Penyimpanan Bahan Makanan Menggunakan PHP dan MYSQL (Studi Kasus: Instalasi Gizi Rumah Sakit Pertamina Balongan Indramavu)

b. Form Data Master “Akun” Admin

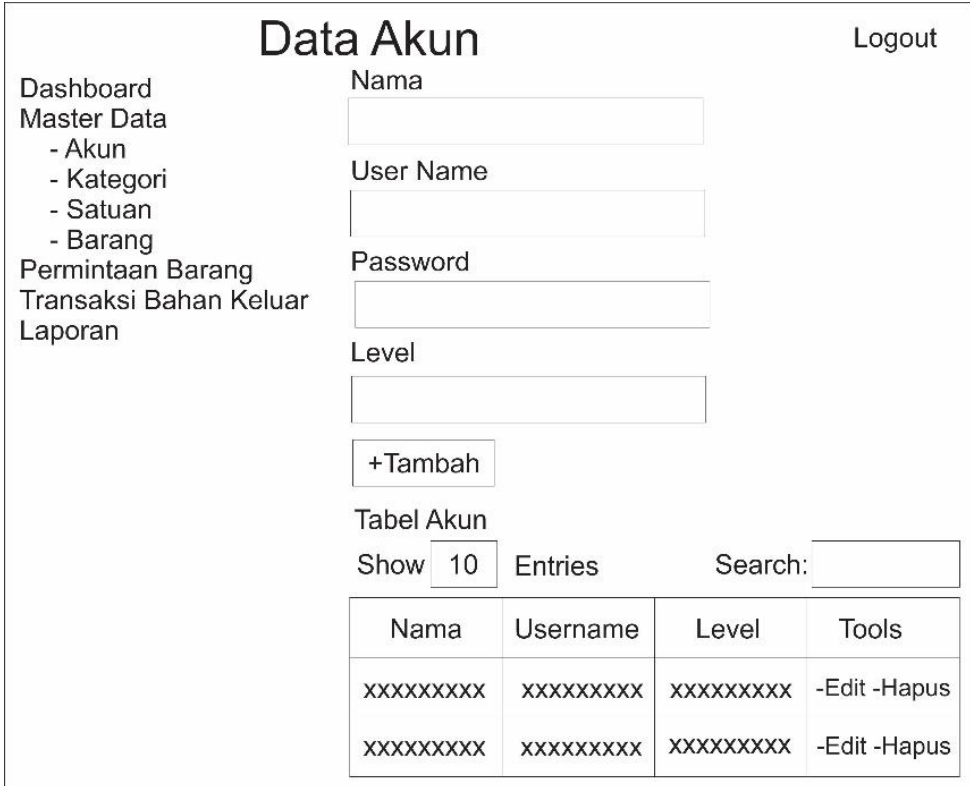

Gambar 3. Desain Data Master "Akun"

c. Form Data Master "Kategori” Admin

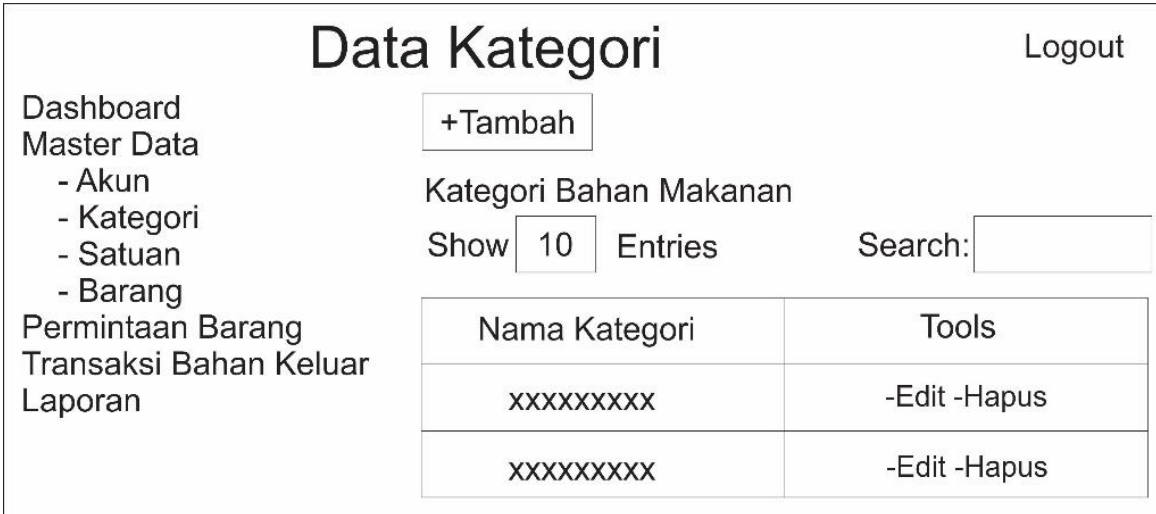

\section{Gambar 4. Desain Data Master "Kategori"}

d. Form Data Master "Satuan" Admin

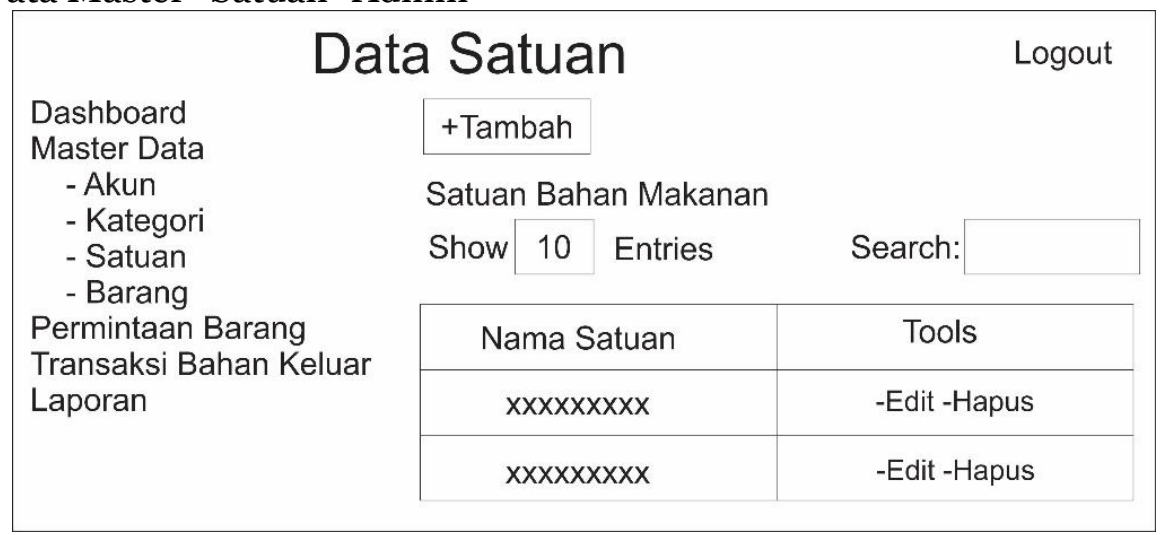

Gambar 5. Desain Data Master "Satuan" 
Maudyna Gita Pratiwi, Tias Beni Purabaya

Sistem Informasi Manajemen Penyimpanan Bahan Makanan Menggunakan PHP dan MYSOL (Studi Kasus: Instalasi Gizi Rumah Sakit Pertamina Balongan Indramayu)

e. Form Data Master "Barang” Admin

\begin{tabular}{|c|c|c|c|c|c|c|}
\hline Da & $\mathrm{Ba}$ & ihan & Mak & nan & & Logout \\
\hline $\begin{array}{l}\text { Dashboard } \\
\text { Master Data }\end{array}$ & + Tam & abah & & & & \\
\hline - Akun & Baha & n Makar & nan & & & \\
\hline $\begin{array}{l}\text { - Kategori } \\
\text { - Satuan }\end{array}$ & Show & 10 & Entries & & arch: & \\
\hline $\begin{array}{l}\text { - Barang } \\
\text { Permintaan Barang } \\
\text { Transaksi Bahan Keluar }\end{array}$ & $\begin{array}{l}\text { Nama } \\
\text { Bahan }\end{array}$ & Kategori & Stok & Satuan & Expired & Tools \\
\hline Laporan & $x x x x$ & $x x x x$ & $x x x x$ & $x x x x$ & $x x x x$ & -Edit-Hapus \\
\hline & $x x x x$ & $x x x x$ & $x x x x$ & $x x x x$ & $x x x$ & -Edit-Hapus \\
\hline
\end{tabular}

\section{Gambar 6. Desain Data Master "Barang"}

f. Form Transaksi Ajukan Bahan Admin

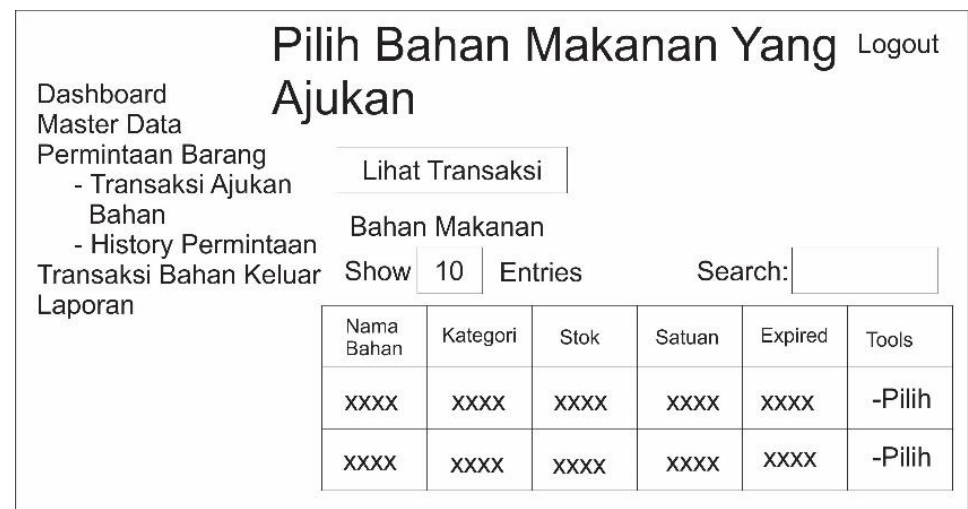

Gambar 7. Desain Transaksi Ajukan Bahan

g. Form Transaksi Bahan Keluar Admin

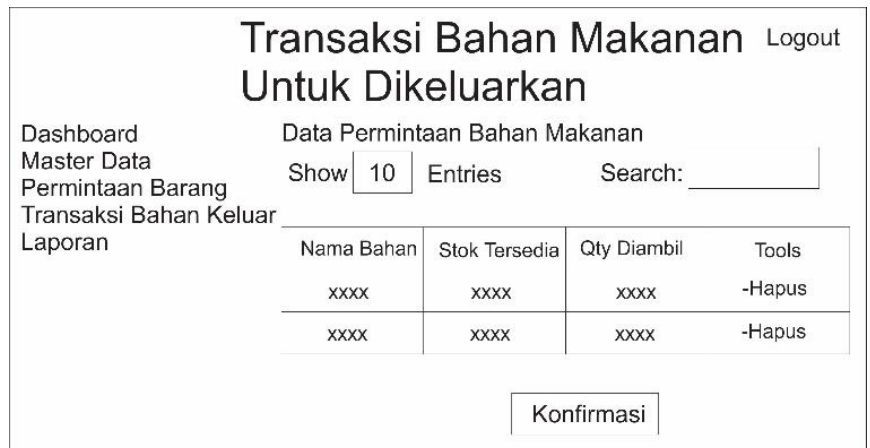

Gambar 8. Desain Transaksi Bahan Keluar

h. Form Permintaan Bahan Keluar Ahli Gizi

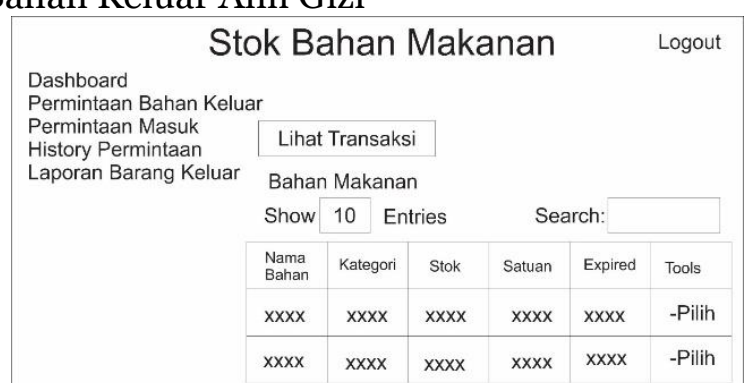

Gambar 9. Desain Permintaan Bahan Keluar 
Maudyna Gita Pratiwi, Tias Beni Purabaya

Sistem Informasi Manajemen Penyimpanan Bahan Makanan Menggunakan PHP dan MYSOL (Studi Kasus: Instalasi Gizi Rumah Sakit Pertamina Balongan Indramayu)

i. Form Permintaan Masuk Ahli Gizi

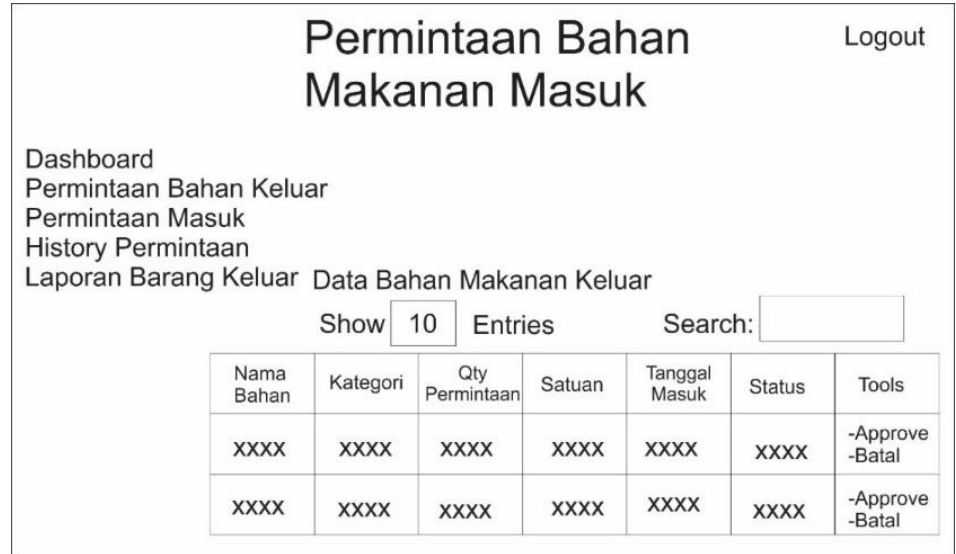

Gambar 10. Desain Permintaan Masuk

j. Form Input Pasien

\begin{tabular}{|c|c|c|c|}
\hline \multirow[b]{2}{*}{ SIPERBAN } & \multicolumn{2}{|c|}{ DATA PASIEN } & Logout \\
\hline & \multicolumn{2}{|c|}{ + Tambah Pasien } & \\
\hline \multirow{3}{*}{$\begin{array}{l}\text { Dashboard } \\
\text { Input Pasien }\end{array}$} & Nama Ruangan & Jumlah Pasien & Tools \\
\hline & $x x x x x x x x$ & $x x x x x x x x$ & $x x x x x x x x$ \\
\hline & $x x x x x x x x$ & $x x x x x x x x$ & $x x x x x x x x$ \\
\hline
\end{tabular}

Gambar 11. Desain Input Pasien

Tampilan Perancangan Output

a. Form History Permintaan Admin

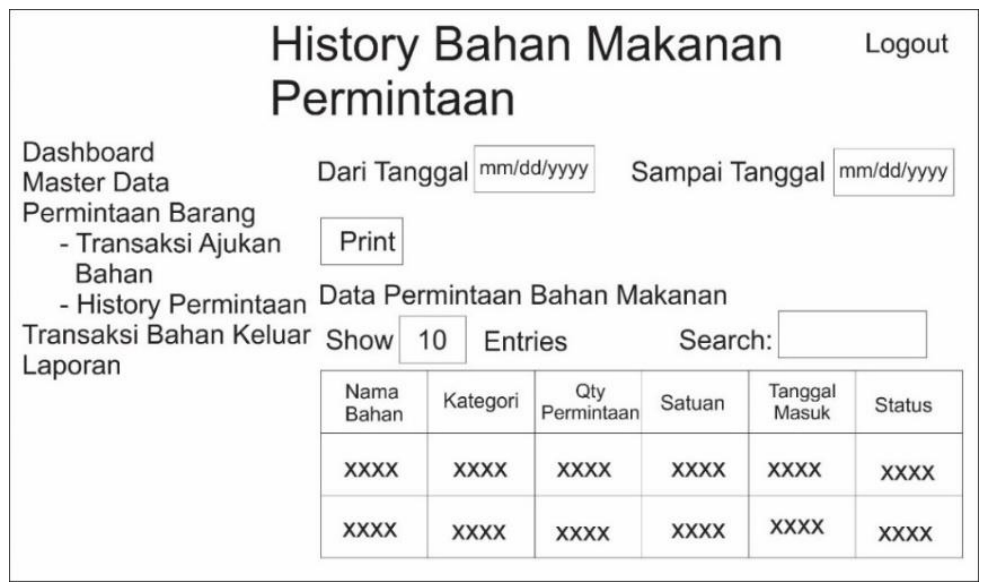

Gambar 12. Desain History Permintaan 
Maudyna Gita Pratiwi, Tias Beni Purabaya

Sistem Informasi Manajemen Penyimpanan Bahan Makanan Menggunakan PHP dan MYSOL (Studi Kasus: Instalasi Gizi Rumah Sakit Pertamina Balongan Indramayu)

b. Form Laporan Bahan Makanan Masuk Admin

\begin{tabular}{|l|l|l|l|l|}
\hline \multicolumn{4}{|c|}{ Laporan Bahan Makanan } \\
Masuk
\end{tabular}

\section{Gambar 13. Desain Laporan Bahan Masuk}

c. Form Laporan Bahan Makanan Keluar Admin

\begin{tabular}{|c|c|c|c|c|c|c|c|}
\hline & $\begin{array}{l}\text { apora } \\
\text { eluar }\end{array}$ & & Bar & an I & Maka & & Logout \\
\hline $\begin{array}{l}\text { Dashboard } \\
\text { Master Data }\end{array}$ & Dari Tar & ggal & $\mathrm{mm} / \mathrm{d}$ & lyyyy & Sampai & anggal & $\mathrm{mm} / \mathrm{dd} / \mathrm{yyyy}$ \\
\hline Transaksi Bahan Keluar & Print & & & & & & \\
\hline $\begin{array}{l}\text { Laporan } \\
\text { - Laporan Bahan }\end{array}$ & Data Bc & han I & Maka & $\tan \mathrm{Ke}$ & uar & & \\
\hline Masuk & Show & 10 & Entr & & Sear & & \\
\hline Keluar & $\begin{array}{l}\text { Nama } \\
\text { Bahan }\end{array}$ & & tegori & $\begin{array}{c}\text { Qty } \\
\text { Keluar }\end{array}$ & Satuan & $\begin{array}{l}\text { Tanggal } \\
\text { Keluar }\end{array}$ & \\
\hline & $x x x x$ & & $x x x$ & $x x x x$ & $x x x x$ & $x x x x$ & \\
\hline & $x x x x$ & & $x x x$ & $x x x x$ & $x x x x$ & $x x x x$ & \\
\hline
\end{tabular}

Gambar 14. Desain Laporan Bahan Keluar

d. Form History Bahan Makanan Permintaan Ahli Gizi

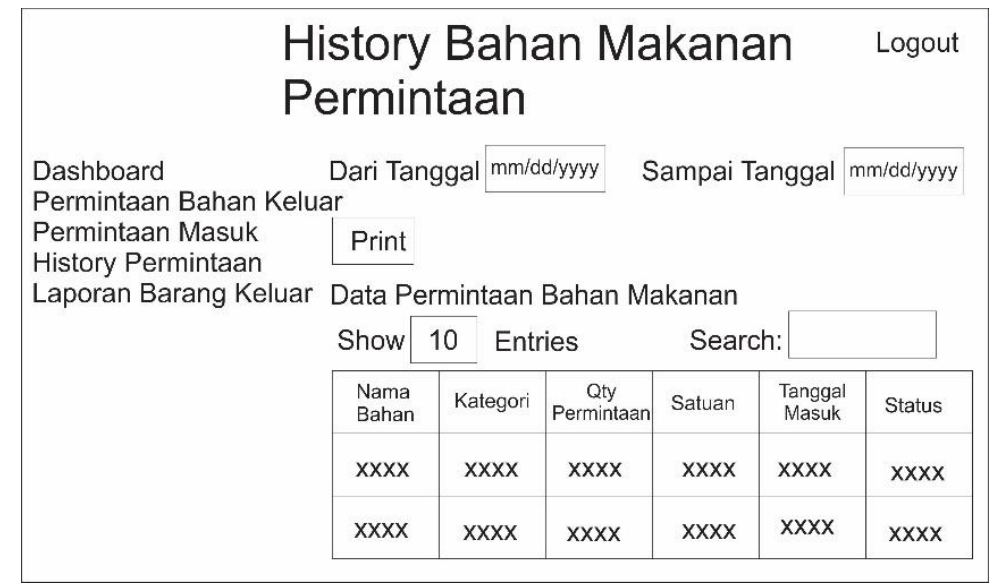

Gambar 15. Desain History Permintaan 
Maudyna Gita Pratiwi, Tias Beni Purabaya

Sistem Informasi Manajemen Penyimpanan Bahan Makanan Menggunakan PHP dan MYSOL (Studi Kasus: Instalasi Gizi Rumah Sakit Pertamina Balongan Indramavu)

e. Form Laporan Bahan Keluar

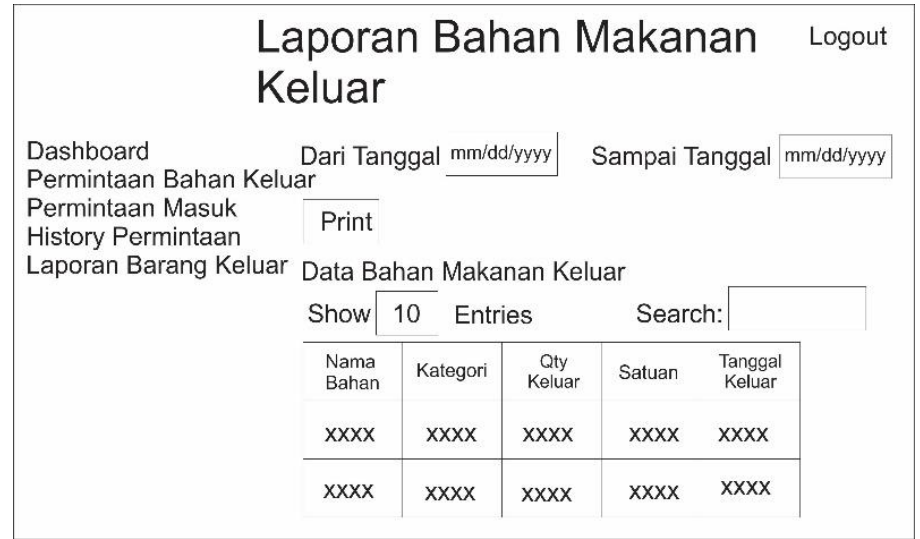

Gambar 16. Desain Laporan Bahan Keluar

\section{Implementasi}

Implementasi sistem merupakan kelanjutan dari kegiatan rancangan program dan dapat dipandang usaha untuk mewujudkan sistem yang telah dirancang setra merupakan tahapan meletakan sistem agar siap untuk diimplementasikan (Sidharta \& Wati, 2015).

1. Kebutuhan perangkat lunak

Untuk membangun dan menjalankan sistem informasi ini dibutuhkan beberapa perangkat lunak pendukung, diantaranya :
a. Sistem Operasi Windows 8
b. Aplikasi MySQL untuk membangun sistem database
c. XAMPP digunakan sebagai web server
d. Visual Studio Code digunakan sebagai pengeditan teks

2. Kebutuhan perangkat keras

Agar aplikasi ini dapat berjalan dengan lancar, maka diperlukan perangkat keras dengan spesifikasi sebagai berikut :
a. Perangkat komputer atau laptop
b. Processor Inter dual Core
c. RAM (Random Access Memory) $2 \mathrm{~Gb}$
d. Harddisk $1 \mathrm{~Gb}$

\section{Uji Coba Sistem}

Pengujian terhadap aplikasi yang dibuat.

1. Form Login

Tabel 8. Tabel Uji Login

\begin{tabular}{llll}
\hline No & Skenario Pengujian & Hasil Yang Diharapkan & Kesimpulan \\
\hline $\mathbf{1}$ & $\begin{array}{l}\text { Mengosongkan username } \\
\text { atau password }\end{array}$ & Sistem menolak & Valid \\
\hline 2 & $\begin{array}{l}\text { Memasukan data username } \\
\text { atau password yang salah }\end{array}$ & Sistem menolak & Valid \\
\hline 3 & $\begin{array}{l}\text { Memasukan data username } \\
\text { atau password yang benar }\end{array}$ & $\begin{array}{l}\text { Sistem masuk lalu ke } \\
\text { tampilan dasbor }\end{array}$ & Valid \\
\hline
\end{tabular}


Maudyna Gita Pratiwi, Tias Beni Purabaya

Sistem Informasi Manajemen Penyimpanan Bahan Makanan Menggunakan PHP dan MYSOL (Studi Kasus: Instalasi Gizi Rumah Sakit Pertamina Balongan Indramayu)

2. Form Data Master Akun Admin

Tabel 9. Tabel Uji Data Master Akun

\begin{tabular}{llll}
\hline No & Skenario Pengujian & Hasil Yang Diharapkan & Kesimpulan \\
\hline 1 & $\begin{array}{l}\text { Mengosongkan nama, } \\
\text { username atau password }\end{array}$ & Sistem menolak & Valid \\
\hline 2 & $\begin{array}{l}\text { Mengosongkan salah satu } \\
\text { diantara nama, username, } \\
\text { ataupun password }\end{array}$ & Sistem menolak & Valid \\
\hline 3 & $\begin{array}{l}\text { Mengisi nama, username } \\
\text { atau password }\end{array}$ & $\begin{array}{l}\text { Data tersimpan pada } \\
\text { tabel penyimpanan }\end{array}$ & Valid \\
\hline
\end{tabular}

3. Form Data Master Kategori Admin

Tabel 10. Tabel Uji Data Master Kategori

\begin{tabular}{|c|c|c|c|}
\hline No & Skenario Pengujian & Hasil Yang Diharapkan & Kesimpulan \\
\hline 1 & $\begin{array}{l}\text { Mengosongkan } \\
\text { kategori }\end{array}$ & Sistem menolak & Valid \\
\hline 2 & Mengisi nama kategori & $\begin{array}{l}\text { Data tersimpan pada } \\
\text { tabel penyimpanan }\end{array}$ & Valid \\
\hline
\end{tabular}

4. Form Data Master Satuan Admin

Tabel 11. Tabel Uji Data Master Satuan

\begin{tabular}{llll}
\hline No & Skenario Pengujian & Hasil Yang Diharapkan & Kesimpulan \\
\hline 1 & Mengosongkan nama satuan & Sistem menolak & Valid \\
\hline 2 & Mengisi nama satuan & $\begin{array}{l}\text { Data tersimpan pada } \\
\text { tabel penyimpanan }\end{array}$ & Valid \\
\hline
\end{tabular}

5. Form Data Master Barang Admin

Tabel 12. Tabel Uji Data Master Barang

\begin{tabular}{|c|c|c|c|c|}
\hline No & Skenario Pengujian & & Hasil Yang Diharapkan & Kesimpulan \\
\hline 1 & $\begin{array}{l}\text { Mengosongkan } \\
\text { barang }\end{array}$ & nama & Sistem menolak & Valid \\
\hline 2 & Mengisi nama satuan & & $\begin{array}{l}\text { Data tersimpan pada } \\
\text { tabel penyimpanan }\end{array}$ & Valid \\
\hline
\end{tabular}

6. Form Transaksi Ajukan Bahan Admin

Tabel 13. Tabel Uji Transaksi Ajukan Bahan

\begin{tabular}{|c|c|c|c|}
\hline & Skenario Pengujian & Hasil Yang Diharapkan & Kesimpulan \\
\hline 1 & $\begin{array}{l}\text { Mengisi banyaknya bahan } \\
\text { yang diajukan }\end{array}$ & $\begin{array}{l}\text { Data tersimpan pada } \\
\text { tabel penyimpanan }\end{array}$ & Valid \\
\hline
\end{tabular}


Maudyna Gita Pratiwi, Tias Beni Purabaya

Sistem Informasi Manajemen Penyimpanan Bahan Makanan Menggunakan PHP dan MYSOL (Studi Kasus: Instalasi Gizi Rumah Sakit Pertamina Balongan Indramayu)

7. Form History Permintaan Admin

Tabel 14. Tabel Uji History Permintaan

\begin{tabular}{llll}
\hline No & Skenario Pengujian & Hasil Yang Diharapkan & Kesimpulan \\
\hline $\mathbf{1}$ & $\begin{array}{l}\text { Memilih tanggal yang ingin } \\
\text { dicetak }\end{array}$ & $\begin{array}{l}\text { Menampilkan data yang } \\
\text { ingin dicetak }\end{array}$ & Valid \\
\hline
\end{tabular}

8. Form Transaksi Bahan Keluar Admin

Tabel 15. Tabel Uji Transaksi Bahan Keluar

\begin{tabular}{llll}
\hline No & Skenario Pengujian & Hasil Yang Diharapkan & Kesimpulan \\
\hline $\mathbf{1}$ & Mengkonfirmasi data & $\begin{array}{l}\text { Data tersimpan pada } \\
\text { tabel penyimpanan }\end{array}$ & Valid \\
\hline
\end{tabular}

9. Form Laporan Bahan Masuk Admin

Tabel 16. Tabel Uji Laporan Bahan Masuk

\begin{tabular}{llll}
\hline No & Skenario Pengujian & Hasil Yang Diharapkan & Kesimpulan \\
\hline $\mathbf{1}$ & $\begin{array}{l}\text { Memilih tanggal yang ingin } \\
\text { dicetak }\end{array}$ & $\begin{array}{l}\text { Menampilkan data yang } \\
\text { ingin dicetak }\end{array}$ & Valid \\
\hline
\end{tabular}

10. Form Laporan Bahan Keluar Admin

Tabel 17. Tabel Uji Laporan Bahan Keluar

\begin{tabular}{llll}
\hline No & Skenario Pengujian & Hasil Yang Diharapkan & Kesimpulan \\
\hline $\mathbf{1}$ & $\begin{array}{l}\text { Memilih tanggal yang ingin } \\
\text { dicetak }\end{array}$ & $\begin{array}{l}\text { Menampilkan data yang } \\
\text { ingin dicetak }\end{array}$ & Valid \\
\hline
\end{tabular}

11. Form Permintaan Bahan Keluar Ahli Gizi

Tabel 18. Tabel Uji Permintaan Bahan Keluar

\begin{tabular}{|c|c|c|c|}
\hline & Skenario Pengujian & Hasil Yang Diharapkan & Kesimpulan \\
\hline 1 & $\begin{array}{l}\text { Mengisi banyaknya bahan } \\
\text { yang diajukan }\end{array}$ & $\begin{array}{l}\text { Data tersimpan pada } \\
\text { tabel penyimpanan }\end{array}$ & Valid \\
\hline
\end{tabular}

12. Form Permintaan Masuk Ahli Gizi

Tabel 19. Tabel Uji Permintaan Masuk

\begin{tabular}{llll}
\hline No & Skenario Pengujian & Hasil Yang Diharapkan & Kesimpulan \\
\hline $\mathbf{1}$ & Meng-approve data & $\begin{array}{l}\text { Data tersimpan pada } \\
\text { tabel penyimpanan }\end{array}$ & Valid \\
\hline
\end{tabular}

13. Form History Permintaan Ahli Gizi

Tabel 2o. Tabel Uji History Permintaan

\begin{tabular}{llll}
\hline No & Skenario Pengujian & Hasil Yang Diharapkan & Kesimpulan \\
\hline $\mathbf{1}$ & $\begin{array}{l}\text { Memilih tanggal yang ingin } \\
\text { dicetak }\end{array}$ & $\begin{array}{l}\text { Menampilkan data yang } \\
\text { ingin dicetak }\end{array}$ & Valid \\
\hline
\end{tabular}

14. Form Laporan Bahan Keluar 
Tabel 21. Tabel Uji Laporan Bahan Keluar

\begin{tabular}{|l|l|l|l|}
\hline No & Skenario Pengujian & Hasil Yang Diharapkan & Kesimpulan \\
\hline $\mathbf{1}$ & $\begin{array}{l}\text { Memilih tanggal yang ingin } \\
\text { dicetak }\end{array}$ & $\begin{array}{l}\text { Menampilkan data yang } \\
\text { ingin dicetak }\end{array}$ & Valid \\
\hline
\end{tabular}

\section{Perawatan Sistem}

Perawatan sistem yang lama tidak sebanding dengan data yang terlibat didalamnya, kurang maksimalnya perawatan mengganggu proses penyimpanan data sehingga memunculkan data-data yang kurang valid mulai dari Backup Data, Updating Database, dan Packing Data.

Kegiatan maintenance merupakan kegiatan pemeliharaan atau perawatan sistem agar sistem tetap berjalan sesuai dengan tujuan dan dapat bertahan lama (Mentari \& Lie, 2017). Pemeliharaan diperlukan khususnya untuk sistem baru terutama untuk menjaga validitas data sehingga tidak memberikan suatu informasi yang menyimpang dari pengolahan data yang diinginkan (Sutabri, 2012). Kegiatan perawatan dapat berupa :

a. Backup data

Backup data dilakukan secara periodik dalam selang waktu tertentu untuk menjaga keamanan data yang tersimpan dalam memori komputer.

b. Updating database

Updating database dilakukan jika sistem akan ditambah sistem yang baru, misalnya dalam sistem akan ditambah pencarian.

c. Packing data

Packing data dilakukan untuk menghapus data-data yang sudah tidak diperlukan lagi sehingga dapat menghemat memori komputer.

Penelitian ini sejalan dengan penelitian yang dilakukan oleh Sarni dalam Skripsinya yang membahas penelitian tentang Sistem Penyimpanan Bahan Makanan Di Tom's Café Tembilahan Kabupaten Indragiri Hilir Provinsi Riau (Sarni \& Achnes, 2017).

\section{KESIMPULAN}

Berdasarkan hasil observasi dan wawancara dalam penyusunan tugas akhir, dapat disimpulkan bahwa kegiatan penyimpanan bahan makanan basah dan bahan makanan kering masih mengggunakan sistem secara manual yaitu menggunakan microsoft excel yang mengakibatkan banyaknya waktu yang terbuang untuk pengerjaannya. Hal itu membuat proses penyimpanan bahan makanan basah dan bahan makanan kering lama dan pengolahan datanya mempunyai banyak kelemahan, seperti pembuatan laporan sering tersendat karena banyaknya data yang tercecer, selain membutuhkan waktu yang lama, keakuratannya juga kurang dapat diterima, karena kemungkinan kesalahan kesalahan sangat besar.

Melihat permasalahan yang terjadi dalam mengatasi hal tersebut dibuatlah aplikasi Sistem Informasi Penyimpanan Bahan Makanan Berbasis Web agar dalam pengolahan datanya bisa lebih efektif dan efisien, dan juga agar prosesnya lebih mudah. Aplikasi ini dirancang dengan menggunakan Use Case Diagram, Activity Diagram, Sequence Diagram, dan Class Diagram.

\section{BIBLIOGRAFI}

Alhamidy, Fuad. (2006). Analisis Model Pengadaan Bahan Makanan Kering berdasarkan Metode EOQ pada Instalasi Gizi Rumah Sakit Roemani Semarang. Program Pasca Sarjana Universitas Diponegoro. Google Scholar

Bassil, Youssef. (2012). A simulation model for the waterfall software development life cycle. ArXiv Preprint ArXiv:1205.6904. Google Scholar 
Maudyna Gita Pratiwi, Tias Beni Purabaya

Sistem Informasi Manajemen Penyimpanan Bahan Makanan Menggunakan PHP dan MYSOL (Studi Kasus: Instalasi Gizi Rumah Sakit Pertamina Balongan Indramavu)

Effendy, Effendy, \& Mulyono, Herry. (2020). Analisis Dan Perancangan Sistem Informasi Pemesanan Dan Penjualan Pakaian Muslim Berbasis Web Pada Toko Hidayatullah Jambi. Jurnal Manajemen Sistem Informasi, 5(4), 526-538. Google Scholar

Gayatri, Isabella Hesti. (2009). Analisis Pengaruh Kualitas Pelayanan Kesehatan Terhadap Kepuasan Pasien Sebagai Pelanggan Eksternal Rumah Sakit Studi Kasus Pada Pasien Rawat Jalan Rumah Sakit Pertamina Indramayu. Google Scholar

Hamzah, D. R. Amir. (2021). Metode Penelitian Kualitatif Rekontruksi Pemikiran Dasar serta Contoh Penerapan Pada Ilmu Pendidikan, Sosial \& Humaniora. CV Literasi Nusantara Abadi. Google Scholar

Hasanah, Hasyim. (2017). Teknik-teknik observasi (sebuah alternatif metode pengumpulan data kualitatif ilmu-ilmu sosial). At-Taqaddum, 8(1), 21-46. Google Scholar

Mentari, Dini, \& Lie, Darwin. (2017). Analisis Pelaksanaan Kegiatan Pemeliharaan (Maintenance) Terhadap Kualitas Produk Pada CV Green Perkasa Pematangsiantar. Maker: Jurnal Manajemen, 3(1), 40-48. Google Scholar

Rosa, Ariani Sukamto. (2016). Rekayasa perangkat lunak terstruktur dan berorientasi objek. Google Scholar

Sarni, Sarni, \& Achnes, Syofia. (2017). Sistem Penyimpanan Bahan Makanan Di Tom's Cafe Tembilahan Kabupaten Indragiri Hilir Provinsi Riau. Riau University. Google Scholar

Sidharta, Iwan, \& Wati, Mirna. (2015). Perancangan dan implementasi sistem informasi urunan desa (URDES) berdasarkan pada pajak bumi dan bangunan. Jurnal Computech \& Bisnis, 9(2), 95-107. Google Scholar

Sutabri, Tata. (2012). Analisis sistem informasi. Penerbit Andi. Google Scholar

Syafar, Arhami. (2012). Studi Manajemen Pelayanan Gizi Pasien di Instalasi Gizi Rumah Sakit Umum Daerah Pangkep Tahun 2012. Universitas Islam Negeri Alauddin Makassar. Google Scholar 